\title{
How does school travel time impact children's learning outcomes in a developing country?
}

\author{
Clifford Afoakwah (D) $^{1} \cdot$ Isaac Koomson ${ }^{2}$
}

Received: 18 April 2020 / Accepted: 1 December 2020

(c) The Author(s), under exclusive licence to Springer Science+Business Media, LLC part of Springer Nature 2021

\begin{abstract}
Nearly $88 \%$ of children in sub-Saharan Africa will not be able to read by the time they complete primary school. We explore this phenomenon by using household data from the Ghana Living Standards Survey to examine the link between school travel time and children's learning outcomes. Using district variations in school density to resolve endogeneity associated with children's travel time to school and their learning outcomes, we find that more than $90 \%$ of children travel on foot to school and this negatively affects their ability to read and write in English or French as well as their ability to read and write in their native languages. We further show that boys, children in rural areas and those who travel more than the 75th percentile travel time (30 minutes) have poorer learning outcomes. Our findings highlight number of class hours missed and poor health as the main channels through which school travel time affects learning outcomes. Policy initiatives to improve children's learning should consider reducing the costs associated with their school travel time. Considering that governments have limited resources with competing needs, policies aimed at reducing travel time should generally target children who commute more than 30 minutes to school and those in rural locations.
\end{abstract}

Keywords School travel time $\cdot$ Reading $\cdot$ Writing $\cdot$ Calculation $\cdot$ Sub-Saharan Africa

JEL classification I21 $\cdot$ I24

Clifford Afoakwah

c.afoakwah@griffith.edu.au

1 Centre for Applied Health Economics, Griffith University, Brisbane, QLD, Australia

2 UNE Business School, Faculty of Science, Agriculture, Business and Law, University of New England, Armidale, NSW, Australia 


\section{Introduction}

Globally, primary school enrolment rate has substantially increased over the past two decades. This achievement is partly driven by the success stories of many developing countries that have implemented universal basic education policies in recent times. In 2018 , for example, gross primary school enrolment rate globally stood at $104 \%$ compared to $97 \%$ in the late nineties. Available data on sub-Saharan Africa (SSA) show that between 1996 and 2009, gross primary school enrolment rate grew by $21.4 \%$. Despite the tremendous increase in school enrolments and attainments, the quality of education presents a new education threat, something UNESCO calls "a learning crisis". Children should be able to read and perform basic calculations by the time they reach primary school completion age (Abadzi 2020), however, 617 million children $(56 \%)$ and adolescents $(44 \%)$ do not achieve the minimum proficiency levels in reading and in mathematics. This implies that one in every two children won't be able to read or do mathematics by the time they complete primary school. The situation is more worrying in SSA, as nearly nine out of ten children aged 6-14 are unable to read or write (UNESCO 2017).

Although many SSA countries have instituted Free Universal Basic Education (FCUBE), such initiatives do not guarantee the quality of education children receive. In theory, free education should reduce the private cost of schooling, create a greater freedom of school choice and increase school enrolments (Gaddah et al. 2016). However, the private cost of schooling in many parts of SSA remains substantial even after introducing free education. This is because children continue to travel long distance for classes and mostly on foot. Such long travel time presents a supply constraint and lead to poor schooling outcomes across all levels of education (Lavy 1996). Most importantly, travel time to and from school can have significant influence on children's learning outcomes. This study tests the hypothesis that long school travel time impedes children's learning outcomes using household data from Ghana. Specifically, we estimate the impact of school travel time on children's ability to read and write in English, French, any of their native language as well as their ability to do written calculation.

Previous studies on distance to school and children's education have primarily focused on only enrolment and school attainments and have neglected intermediate outcomes (Lavy 1996; Tansel 1997; Grootaert and Partinos 1999; Handa 2002). While school attainment reveals long-term schooling outcomes, it masks vital information on the child's performance in school, which is critical for the smooth progression of the child in school. Also, in a context where primary education is free, enrolment and attainment may not reveal the impact of travel time on children's education.

Apart from focusing on school enrolment and attainments, previous studies have also measured distance using community variables. As noted by Filmer (2007), estimating the average effect of school availability on outcomes would mask the heterogeneity in the relationship between distance and enrolment. This is because households within the same community vary significantly in terms of proximity, wealth and time use, which ultimately predicts children's commuting time to school. In a study by Burke and Beegle (2004) in Northwestern Tanzania, the authors estimated the predictors of school attendance after controlling for child, household 
and community characteristics. Their finding was that education policies that seek to increase school attendance should focus on the drivers within the household. This suggests the heterogenous nature of households which has an implication on children's schooling decisions and outcomes.

We contribute to this important literature by using nationally representative household data from the Ghana Living Standards Survey to examine the impact of school travel time on children's learning outcomes. More specifically, we look at how travel time affects children's ability to read and write in English/French, their ability to read/write in the native languages as well as their ability to do written calculations. By doing so, we make a number of contributions to the literature. First, unlike previous works, we use novel household data with better learning outcome measures and more fine-grained measure of school travel distance (which are often rare in developing countries) to estimate the effect of school travel time on learning outcomes. Second, we examine outcomes which have significant impact on children's human capital formation but have largely been ignored in the literature. In doing so, we use a better identification approach to resolve the endogeneity between school travel time and learning outcomes. Finally, we interrogate the potential channels through which school travel time affects children's learning outcomes.

The rest of the study is organised as follows: Section 2 presents a contextual background of education in Ghana, which is followed by the empirical identification approach utilised in the study in Section 3. Section 4 describes the data used for the analysis while Section 5 discusses the results. Section 6 presents more nuanced analysis and some robustness checks which is followed by the conclusion in Section 7.

\section{Background}

\subsection{Study context}

Ghana gained independence in 1957 from the British and was the first sub-Saharan African country to do so at the time. Educational outcomes at the time were not encouraging. In 1971, gross primary school enrolment rate for example, was $64.09 \%$, which was below the global primary school enrolment rate of $89.15 \%$ (World Bank 2019), partly due to lack of investment in educational infrastructure. Over the years, successive governments have significantly restructured the educational sector with huge investments. In 1992, Ghana introduced Free Compulsory Universal Basic Education (FCUBE) with the aim of providing quality basic education for all schoolaged children by 2005 and was constitutionally binding on all governments. This was followed with the provision of school meals to children in schools in deprived districts - the Ghana School Feeding Program (GSFP). As of 2015, the GSFP reached out to more than 1.6 million primary school children across 170 districts in the country (Gelli et al. 2019). Primary school enrolment has since increased with gross enrolment rate estimated to be 105.51\% in 2017 (World Bank 2019), exceeding the global average of $103.65 \%$. Despite the success chalked with regards to enrolment, learning outcomes remain a concern. This study interrogates this issue by doing an in-depth analysis of how school travel time affects children's learning outcomes. 


\subsection{Previous works}

The study is conducted within the framework of Becker's (1975) human capital theory. Human capital includes the knowledge, skills, competences and attributes that allow people to contribute to their personal and social well-being, as well as their productivity (Brian 2007). The human capital theory values knowledge and skills as instrumental since they help improve people's productivity and increased earnings (Quiggin 1999). From a broader perspective, the theory is conceptualised to include skills that do not only contribute directly to market returns but also to non-market returns. In building one's human capital, the household, government and society at large play an important role and are expected to sacrifice current income for education, which is anticipated to produce future monetary and non-monetary returns (Mincer 1958; Schultz 1961). Previous studies have acknowledged children's early acquisition of literacy skills (reading, writing and numeracy) as essential for later learning and success and for that reason, parent's and societies' investment in this process is considered the most cost-effective form of human capital development (Heckman 2000; Leibowitz 2003; World Bank 2003). Children's ability to effectively acquire basic literacy skills can be linked to quality of teaching, which is directly linked to the quality of the school attended and to the amount of instructional time available to the child (Fredrick and Walberg 1980; Cattaneo et al. 2017). Among many possibilities, the linkages between children's ability to read and write, school quality and instructional time can further be linked to travel distance to school. For instance, children who travel long distance to school are more likely to miss some hours of daily instructions and also miss out on important opening announcements and academic activities which can adversely affect performance (Fredrick and Walberg 1980; Cattaneo et al. 2017). This shows that travel distance can have an influence on human capital development through its influence on children's learning outcomes.

Empirical studies on distance and children's education have shown that distance impedes school participation. Frenette (2006) and Frenette (2004) used data from Canada to show that high school students living far from the local university were less likely to attend university, especially among those from low income households. Similar findings were ascertained in Germany by Spiess and Wrohlich (2010). The authors found that distance to the nearest university negatively affects university participation, which is mainly explained by high transaction cost rather than neighbourhood effect. The evidence from Ireland and England are consistent that longer distance to school significantly impedes children's decision to participate in higher education England (Dickerson and McIntosh 2013; Flannery and Cullinan 2014). The literature from SSA has largely focused on primary school enrolment and attainment. Lavy (1996) investigated the impact of distance on enrolment and attainment using logit and ordered probit approaches respectively in rural Ghana. His main finding was that distance to primary school impedes enrolment with an elasticity of 0.07. A similar study was conducted by Tansel (1997), in which she explored the effect of distance on primary school enrolment and middle school attainment in Ghana and Côte d'Ivoire using household surveys. Specifically, she found that distance reduced the probability of school enrolment and years of attainment in both countries, with the larger effect depicted among girls than boys. 
Grootaert and Partinos (1999) further showed that the impact of travel time on schooling and child labour was more evident among rural Ivorians than those in urban areas. The negative impact of such supply-side constraint on school enrolment was confirmed in Mozambique (Handa 2002).

The review of existing literature shows that the distance-education nexus has either focused on university level (mostly in developed countries) or on primary school enrolment and attainment, with no focus on intermediate learning outcomes. We fill this gap in the literature by using fine-grained household data from Ghana to estimate the effect of school travel time on a range of children's learning indicators.

\section{Empirical implementation}

\subsection{The model}

In this study, we conceptualise children's learning outcome as being determined by both supply and demand side factors. Specifically, we model the child's learning outcome to depend on his/her daily travel time to and from school and several confounding demand-side variables. Our main empirical equation is specified as:

$$
\text { Learn }_{\text {imt }}=\alpha+\text { Btravel_time }{ }_{i m t}+\partial Z_{\text {imt }}^{\prime}+\vartheta_{m}+\sigma_{t}+\mu_{i}
$$

where Learn captures five learning outcomes including the child's ability to read English or French, ability to write in English or French, ability to write in any native language, ability to read in any native language and ability to do written calculation. travel_time represents the time (in minutes) used by the child in commuting to and from school. $Z^{\prime}$ is a vector of control variables for child, parent, household and school characteristics. $m$ is the interview month and $t$ is the interview year. Control variables included in our model are child gender, age, free meal in school, whether the school is public, household size, gender of household head, the age of the household head as well as a squared age term to capture any non-linear relationship between the household head's age and their children's education. We include per capita household education expenditure in our model to capture the price of education. Consistent with previous studies, we estimate Eq. (1) using the Linear Probability Model (LPM). The coefficients from the LPM are easy to interpret as marginal effects (Caudill 1988; Afoakwah et al. 2020a, 2020b). This is also because the coefficients of the LPM directly align with those of the two-stage least squares (2SLS) which is employed to resolve the endogeneity problem.

\subsection{Potential endogeneity}

Estimating the effect of travel time on children's learning outcomes casually may produce inconsistent estimates due to the problem of endogeneity emanating from omitted variable(s). Specifically, the distribution of schools across communities may not be random and might be influenced by timing, placement, and the location of new school facilities (Lavy 1996). These supply side determinants are mostly driven by the interaction between the central government and local authorities. This nonrandom distribution of schools, which is unobservable, is likely to be correlated with 
the error term in Eq. (1) leading to biased estimate if not resolved. Identification, therefore, relies on variations in school concentration across districts while controlling for month and year of interview fixed effects.

$$
\text { travel_time }_{i m t}=\rho+\epsilon S \text { Ch_concernt }+\pi Z_{i m t}^{\prime}+\vartheta_{m}+\sigma_{t}+\mu_{i}
$$

Similar to Alderman et al. (2001), we use variations in school concentration across districts as an instrument to establish our identification strategy since the instrument satisfies both the relevance and validity conditions. This is depicted as Sch_concernt in Eq. 2 after controlling for month and year of interview fixed effects. Basic school concentration is measured as average travel time to school among communities in each district, hence, our instrument varies across districts. The community data from the GLSS contain information on distance to the nearest primary, Junior High School (JHS) or Senior High School (SHS). Using this information, we compute the average travel time in each district. Districts are the smallest administrative levels in Ghana. The focus of this paper is to utilise exogenous variation in school density to identify children's commuting time from home to school since households within a district differ substantially regarding their proximity to schools. To satisfy the exclusive restriction condition, we perform a couple of things. First, since children who travel long distance to school are likely to live in poor or rural-located homes and may likely have poor learning outcomes, we control for both household poverty status and a dummy for whether the household is located in rural area in our model. Second, children who travel long distance to school are likely have parents with low levels of education who may end up having low marginal benefit for their children's education (Abdul-Mumuni and Koomson 2019; Afoakwah et al. 2020; Handa 2002), we include the level of education of the household head in our model as well as per capital household educational expenditure. Third, the relationship between school travel time and learning outcomes might confound with the health of the child, hence, we isolate this confounder by controlling for the disability status and whether the child receives free meal in school. ${ }^{1}$ Finally, we include regional dummies for the ten administrative regions of Ghana to capture other regional level factors such as poverty, access to health clinics, employment, poor infrastructure and population density that can systematically drive children's education but are not directly included in our model. By controlling for these confounding variables, we argue that the school concentration across district does not directly affect children's learning outcomes but through their travel time to school. We statistically test for the validity of our instrument by using the Cragg-Donald Wald F statistic for weak identification test.

\section{Data and descriptive statistics}

Data are sourced from the seventh round of the Ghana Living Standards Survey (GLSS 7). The GLSS is the most comprehensive and representative national household survey which has been ongoing since 1987. The survey aims at measuring

\footnotetext{
${ }^{1}$ Previous studies have shown the positive impact of free school meal on children's educational outcomes (Afridi 2011). 
the living conditions and wellbeing of the Ghanaian population (GSS 2019). The GLSS7 took place in 2016/17, and has vital information on household poverty, education, health, and socio-demographic characteristics. The education module of the survey included information on children's learning outcomes on reading, writing and calculation skills which are useful for our study. Specifically, the following five questions are used as our main learning outcomes in this study:

(1) “Can 'name' read a phrase in English or French"?

(2) "In which Ghanaian language can 'name' read"?

(3) "Can 'name' write in English or French"?

(4) "In what Ghanaian language can 'name' write"?

(5) Can 'name' do written calculation"?

We focus on these outcomes because they are part of the curriculum and children are taught how to read and write in English, French and at least one Ghanaian Language as well as mathematics. It is therefore compulsory for children to pass these subjects in their Basic Education Certificate Examination (BECE) before being admitted into Senior High School. Typically, the education system in Ghana is divided into three cumulative parts: basic, senior high school (SHS) and tertiary. Basic education is the first nine years of formal education and ends with a general BECE. Children's ability to perform these tasks is a good indicator of their learning outcomes. We focus on children of basic school going age, which usually ends at age 15. However, in our modelling, we control for whether the child enrolled late in school or not to minimise any biasness coming from late enrolments.

The descriptive statistics in Table 1 shows that $68.4 \%$ of children can write in English or French while $70.8 \%$ can read English or French. Interestingly, while only $33.1 \%$ can write in their native language, $36.3 \%$ can read in any native language. Also, $77.2 \%$ can perform written calculation task. On the average, children travel 19 minutes to and from school and mostly on foot (90.23\% as shown in Appendix 1). Our sample is made up of $51.7 \%$ males with an average age of 10 years. $21.2 \%$ receive free meals in school and while most children attend public schools $(80.5 \%)$.

\section{Results}

\subsection{Core findings on learning outcomes}

We start by discussing results from the full sample as shown in Table 2. We report both results for the LPM and 2SLS for comparison. The coefficients of the instrument from the first-stage regression show that a minute increase in the average travel time in a district is associated with an increase in children's travel time by $56 \mathrm{sec}$ $(0.932 * 60)$ and is statistically significant across all specifications. That is, availability of many schools in a district significantly reduces children's travel time from their homes to school. In addition, the Cragg-Donald Wald F statistic for test of weak instrument exceeds the critical value of 10, suggesting that our instrument is valid. The results from the ordinary least squares (OLS) shows downward bias estimates of the negative relationship between travel time and learning outcomes. Therefore, we restrict our discussion to the results from the 2SLS (IV) estimates. 
Table 1 Descriptive statistics

\begin{tabular}{|c|c|c|c|}
\hline Variable & Variable description & Mean & SD \\
\hline Write in English/French & Whether the child can write in English or French & 0.684 & 0.465 \\
\hline Read English/French & Whether the child can read English or French & 0.708 & 0.455 \\
\hline Write in native language & Whether the child can write in any native language & 0.331 & 0.471 \\
\hline Read native language & Whether the child can read any native language & 0.363 & 0.481 \\
\hline Do written calculation & Whether the child can do written calculation & 0.772 & 0.420 \\
\hline Travel time & Travel time to and from school & 19.361 & 14.24 \\
\hline Travel distance within districts & Average travel time to basic schools in a district & 14.11 & 2.344 \\
\hline Male & Male child & 0.517 & 0.500 \\
\hline Child age & Age of the child in years & 10.39 & 2.86 \\
\hline Free meal & Whether the child receives free meal in school & 0.212 & 0.409 \\
\hline Household size & Number of persons in the household & 6.90 & 3.375 \\
\hline Late enrolment & Whether the child enrolled late at primary school & 0.303 & 0.460 \\
\hline Any disability & Whether the child has any form of disability & 0.212 & 0.488 \\
\hline Public school & Whether the child attend public school & 0.805 & 0.396 \\
\hline Female head & Female headed household & 0.307 & 0.461 \\
\hline $\begin{array}{l}\text { Log per capita education } \\
\text { expenses }\end{array}$ & Log annual per capita educational expenses & 5.448 & 1.508 \\
\hline Head age & Age of the household head & 49.68 & 12.996 \\
\hline \multicolumn{4}{|l|}{ Head education } \\
\hline No education & $\begin{array}{l}\text { Whether the household head has completed no } \\
\text { education }\end{array}$ & 0.393 & 0.488 \\
\hline Basic & $\begin{array}{l}\text { Whether the household head has completed basic } \\
\text { education }\end{array}$ & 0.475 & 0.415 \\
\hline SHS & $\begin{array}{l}\text { Whether the household head has completed SHS } \\
\text { education }\end{array}$ & 0.078 & 0.269 \\
\hline Tertiary & $\begin{array}{l}\text { Whether the household head has completed tertiary } \\
\text { education }\end{array}$ & 0.053 & 0.224 \\
\hline
\end{tabular}

SD Standard deviation, SHS Senior High School

Column 1 shows that one-minute increase in travel time to school reduces children's ability to write English or French by 1.1 percentage points. The corresponding negative impact of travel time on children's ability to read English or French is 0.7 percentage points. A larger negative effect of travel time is found for children's ability to read and write in their native languages. One minute of traveling time is associated with a reduction in children's ability to write and read in their native languages by 2.6 and 2.2 percentage points respectively. Although, travel time to school is negatively linked to children's ability to do written calculation, this is not statistically significant as shown in Column 5. These findings are consistent with previous studies that found that distance to school impeded enrolments and school attainments (Lavy 1996; Tansel 1997; Grootaert and Partinos 1999; Handa 2002). However, our findings provide more insight on the intermediate impact of travel time on children's education. 


$$
\text { 盲 }
$$




\subsection{Gender differences in learning outcomes}

Travel time to school may have varying impact among boys and girls depending on how household activities are allocated between them. If for example, girls are required to partake in morning household chores before going to school, they are likely to be more affected by the negative impact of school travel time compared to boys. In addition, estimates from UNESCO (2017) show a gender difference in learning outcomes in SSA - while $90 \%$ of girls are unable to read, the corresponding figure for boys is $85 \%$. Hence, it is important to investigate how school travel time contributes to such disparity. Panel A of Table 3 shows the gender differences in the impact of school travel time on children's learning outcomes. We observe that across all learning outcomes, boys are more impacted by the negative effect of travel time and the difference ranges from 1.0-1.5 percentage points. Consistent with the core finding, the gender-specific analysis shows that school travel time has statistically significant effect on children's ability to perform written calculation. The relatively lower impact of school travel time on learning outcomes among girls is partly because, relative to boys, girls have high reading and writing abilities. Appendix 2 shows that primary school girls in Ghana have better reading and writing abilities in both English or French and their native languages compared to boys, which is contrary to evidence in the extant literature for SSA.

\subsection{Rural-urban differences in learning outcomes}

We now turn our attention to the rural urban differences in the impact of school travel time on children's learning outcomes. Children in rural areas may differ from those in urban areas in terms of socioeconomic backgrounds, which may expose them to larger negative impacts of travel time to school. At the same time, those in urban areas may have different coping strategies to mitigate the negative impact of school travel time. Panel B in Table 3 shows that the negative impact of travel time on children's ability to read and write in English or French language, their ability read and write in their native languages and their ability to do written calculation are larger among those in rural areas than their peers in urban areas. The rural difference in the negative impacts of travel time on learning outcomes range from 0.3 percentage points for children's calculation skills to 1.8 percentage points for children's ability to write in their native languages. As shown in the summary statistics in Appendix 2, children in urban areas have better reading, writing and calculation skills than their peers in rural areas.

\subsection{Potential channels}

Finally, we explore the possible channels through which travel time to school would affect children's' learning outcomes. The survey questionnaire includes questions on the number of class hours the child missed in the past week; whether the child suffered from any illness or injury in the past two weeks; consulted health practitioner in the past two weeks or has been hospitalised for any illness in the past 12 months preceding the survey. We use these four variables to tease out the potential channels for the findings in this study as summarised in Table 4. Column 
Table 3 IV estimate for the effect of distance to school on learning outcomes across different genders and locations

\begin{tabular}{|c|c|c|c|c|c|}
\hline $\begin{array}{l}\text { Panel A: Gender } \\
\text { differences }\end{array}$ & $\begin{array}{l}\text { Write English/ } \\
\text { French }\end{array}$ & $\begin{array}{l}\text { Read English/ } \\
\text { French }\end{array}$ & $\begin{array}{l}\text { Write native } \\
\text { language }\end{array}$ & $\begin{array}{l}\text { Read native } \\
\text { language }\end{array}$ & $\begin{array}{l}\text { Do written } \\
\text { calculation }\end{array}$ \\
\hline Travel time $\mathrm{X}$ Male & $-0.013 * * *(0.005)$ & $-0.010 * *(0.004)$ & $-0.015 * * *(0.005)$ & $-0.012 * * *(0.005)$ & $-0.004(0.004)$ \\
\hline Child characteristics & Yes & Yes & Yes & Yes & Yes \\
\hline School characteristic & Yes & Yes & Yes & Yes & Yes \\
\hline Household characteristic & Yes & Yes & Yes & Yes & Yes \\
\hline Regional dummies & Yes & Yes & Yes & Yes & Yes \\
\hline Interview month & Yes & Yes & Yes & Yes & Yes \\
\hline Interview year & Yes & Yes & Yes & Yes & Yes \\
\hline \multicolumn{6}{|l|}{ Instrument } \\
\hline Distance X Male & $0.933 * * *(0.100)$ & $0.924 * * *(0.104)$ & $0.938 * * *(0.100)$ & $0.938 * * *(0.100)$ & $0.938 * * *(0.100)$ \\
\hline $\begin{array}{l}\text { Cragg-Donald Wald F } \\
\text { statistic }\end{array}$ & 86.36 & 83.19 & 87.87 & 87.87 & 87.85 \\
\hline $\mathrm{N}$ & 3704 & 3704 & 3704 & 3704 & 3704 \\
\hline \multicolumn{6}{|l|}{ Panel B: Urban differences } \\
\hline Travel time $\mathrm{X}$ Urban & $-0.013 * * *(0.003)$ & $-0.009^{* * *}(0.003)$ & $-0.018 * * *(0.004)$ & $-0.015^{* * *}(0.004)$ & $-0.003 * * *(0.003)$ \\
\hline Child characteristics & Yes & Yes & Yes & Yes & Yes \\
\hline School characteristic & Yes & Yes & Yes & Yes & Yes \\
\hline Household characteristic & Yes & Yes & Yes & Yes & Yes \\
\hline Regional dummies & Yes & Yes & Yes & Yes & Yes \\
\hline Interview month & Yes & Yes & Yes & Yes & Yes \\
\hline Interview year & Yes & Yes & Yes & Yes & Yes \\
\hline \multicolumn{6}{|l|}{ Instrument } \\
\hline Distance X Urban & $1.064 * * *(0.097)$ & $1.061 * * *(0.097)$ & $1.069 * * *(0.097)$ & $1.069 * * *(0.097)$ & $1.069 * * *(0.097)$ \\
\hline $\begin{array}{l}\text { Cragg-Donald Wald F } \\
\text { statistic }\end{array}$ & 119.92 & 119.22 & 122.35 & 122.62 & 122.58 \\
\hline$N$ & 3704 & 3704 & 3704 & 3704 & 3704 \\
\hline
\end{tabular}

All columns include control variables for whether the child receives free meal in school, whether the child has any disability, age of the child, whether the child enrolled in school late, age of the household head, a squared term age of household head, level of education of the household head, household size, a dummy for rural household, whether the household head is a female, educational expenditure, household poverty status, whether the school is a public school, month of interview and year of interview

Robust standard errors are in parenthesis $* * * p<0.01, * * p<0.05,{ }^{*} p<0.1$

$I V$ instrumental variables estimation

1 shows that children who travel longer distance to school are more likely to miss some class hours. A minute increase in travel time to school increases lesson times missed by about 3 minutes $(0.047 * 60)$. Similarly, column 2 shows that longer travel time increases the chance of visiting a health practitioner by 0.30 percentage points and being hospitalised for any illness by 0.4 percentage points. This suggests that longer travel time to school negatively affects children's learning outcomes through increased class hours missed and poor health. It is important to note that $90.23 \%$ of children walk to and from school daily as shown in Appendix 1, which means that such children are more likely to get to school late or fall sick due to any illness, causing them to miss classes. Long class hours missed, partly due to sick days impacts student's ability to consolidate and automatize basic skills since their brains require more time and constant practice to do so (Abadzi 2007). Linking this to the human capital theory implies that societies' inability to provide the infrastructure 


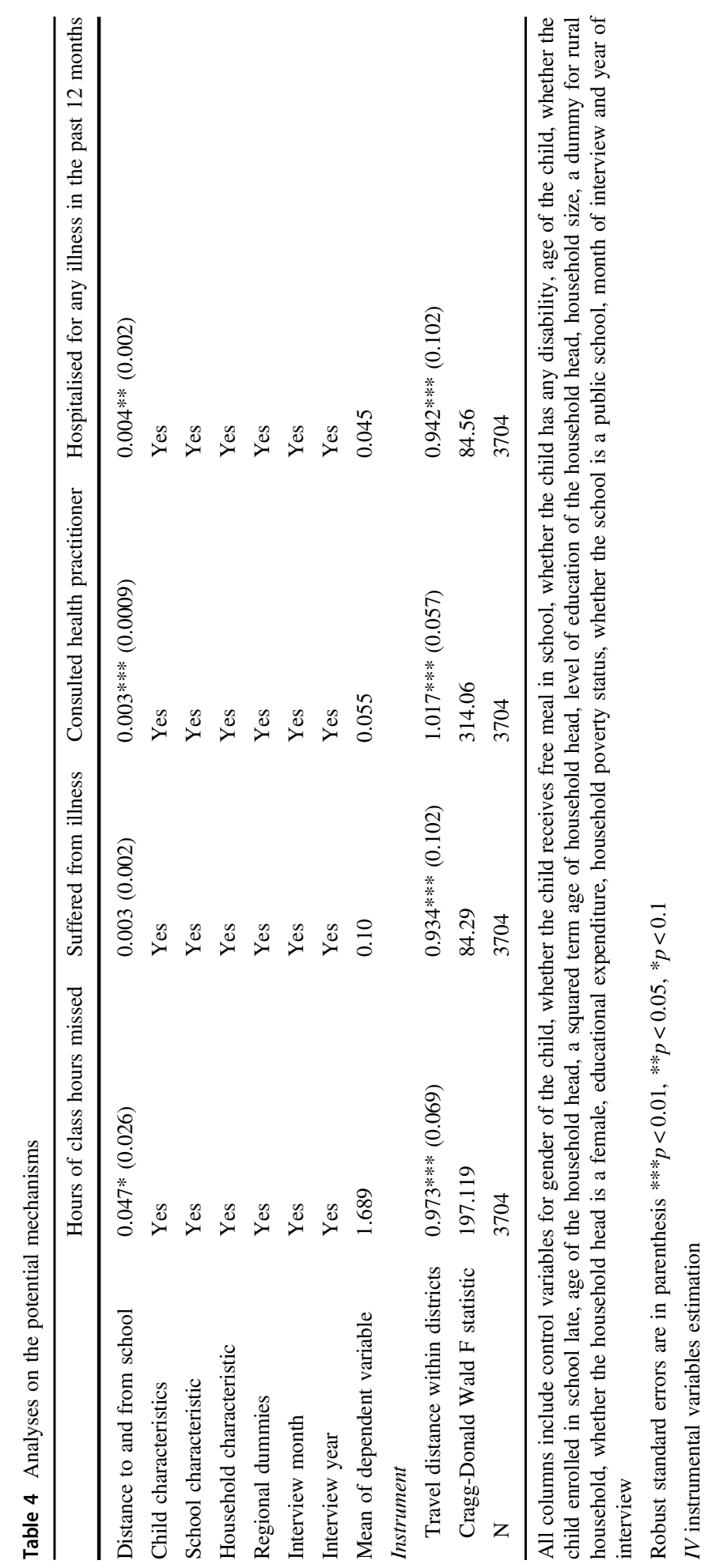


needed to reduce children's travel time to school is likely have a long term effect of producing adults with too little of the skills needed to effectively function as productive members which will also hamper the development of the individual and social at large (Brian 2007).

\section{Additional results and robustness checks}

\subsection{Non-linear effect of school travel time on children's learning outcomes}

It is possible that the negative effect of school travel time on learning outcomes is not linearly related to travel time but rather varies across the distribution of school travel time. Hence, we conduct percentile analysis to further explore the variation in the negative relationship established in Table 2. The results in Table 5 shows that the impact of school travel time on learning outcomes starts to be negative after the $50^{\text {th }}$ percentile (median) travel time, which is 17 minutes. That is, the threshold travel time where cost starts to rise is 17 minutes. The negative effect increases substantially when we consider children's traveling time above the 75 th percentile travel time (30 minutes). Among such children, their learning ability reduces between 2.1-2.5 percentage points.

\subsection{Focusing on only those who travel on foot to school}

Appendix 1 shows that about $90 \%$ of children travel to school on foot, hence we restrict the analyses to only those who travel to school on foot. Our hypothesis is that children who walk to school are more likely to have their learning outcomes compromised compared to those who travel by other means. Table 6 shows that children who travel on foot have low reading, writing and calculation skills and the estimates are larger than those from the pooled sample (especially for writing and reading in native languages). Appendix 3 shows the correlation between modes of travel and percentile distribution of travel time. It shows that $36 \%$ of those who travel on foot walk for more than 30 minutes to school. This percentage is lower than all the other modes of transport to school, which suggests that distance to school by itself may not directly affect children's education if households have diverse coping strategies which prevent children from walking long distance to school. These coping strategies reduce their commuting time, thereby improving their learning outcomes. Such coping strategies which include access to school bus, public transport, motorcycle, or even bicycle will have a long-term effect of improving children's learning abilities.

\subsection{Sample attrition issues}

Next, we check whether sample attrition driven by early school drop out by older children compromises our estimates. We exclude children who are aged 14-15 years from the sample. The results in Table 7 shows slightly larger estimates for writing and reading in English/French language as well as children's ability to do written calculations. However, the findings on writing and reading native language are similar to the core findings in Table 2. This shows that sample attribution does not 


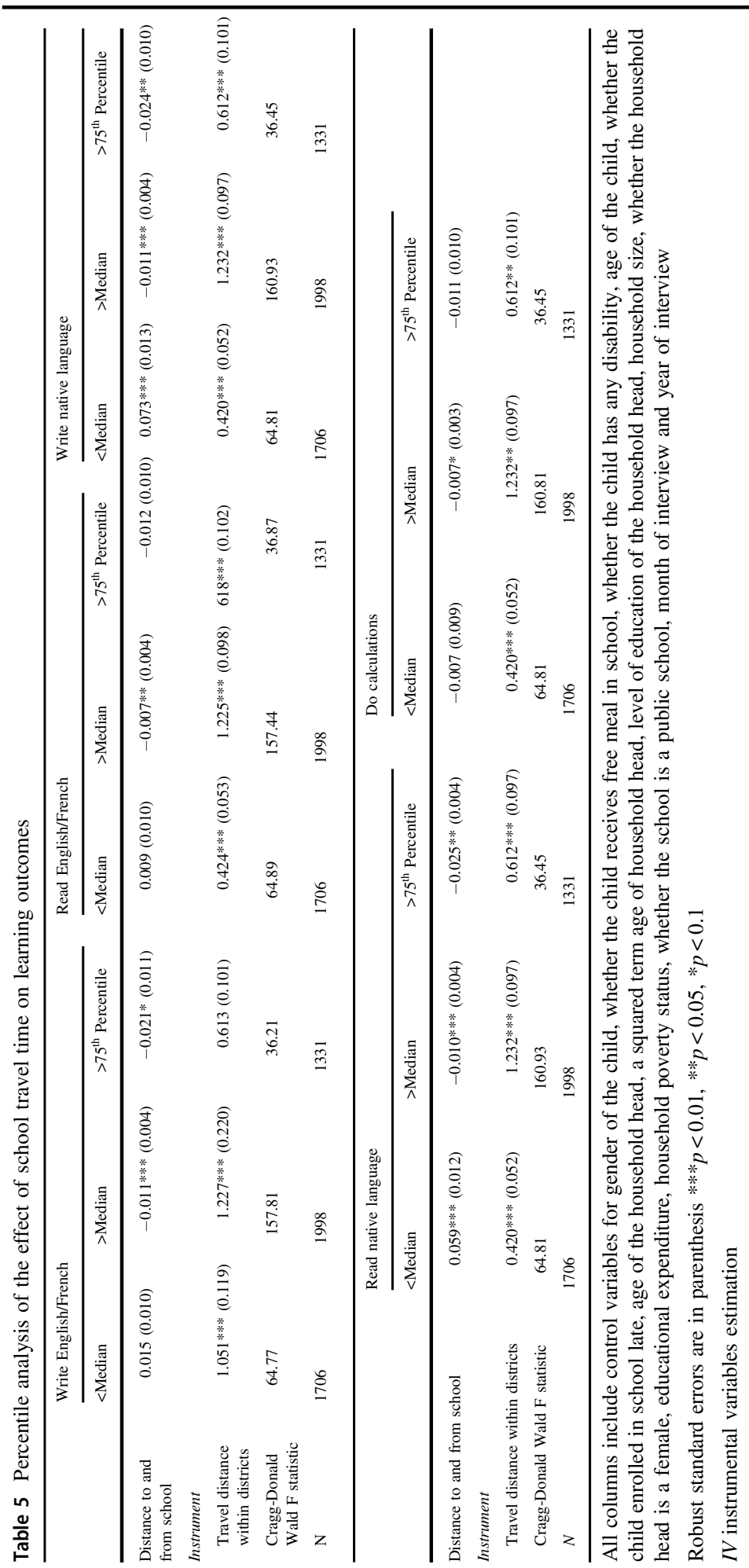


Table 6 Restricted analyses for only those who travel on foot to school

\begin{tabular}{|c|c|c|c|c|c|}
\hline & $\begin{array}{l}\text { Write English/ } \\
\text { French }\end{array}$ & $\begin{array}{l}\text { Read English/ } \\
\text { French }\end{array}$ & $\begin{array}{l}\text { Write native } \\
\text { language }\end{array}$ & $\begin{array}{l}\text { Read native } \\
\text { language }\end{array}$ & $\begin{array}{l}\text { Do written } \\
\text { calculation }\end{array}$ \\
\hline & IV & IV & IV & IV & IV \\
\hline Distance to and from school & $-0.010 * *(0.003)$ & $-0.005 *(0.003)$ & $-0.024 * * *(0.004)$ & $-0.020 * * *(0.004)$ & $-0.003(0.003)$ \\
\hline Child characteristics & Yes & Yes & Yes & Yes & Yes \\
\hline School characteristic & Yes & Yes & Yes & Yes & Yes \\
\hline Household characteristic & Yes & Yes & Yes & Yes & Yes \\
\hline Regional dummies & Yes & Yes & Yes & Yes & Yes \\
\hline Interview month & Yes & Yes & Yes & Yes & Yes \\
\hline Interview year & Yes & Yes & Yes & Yes & Yes \\
\hline \multicolumn{6}{|l|}{ Instrument } \\
\hline $\begin{array}{l}\text { Travel distance within } \\
\text { districts }\end{array}$ & $1.010 * * *(0.104)$ & $1.001 * * *(0.105)$ & $0.996 * * *(0.104)$ & $0.996 * * *(0.104)$ & $0.996^{* * * *}(0.104)$ \\
\hline $\begin{array}{l}\text { Cragg-Donald Wald F } \\
\text { statistic }\end{array}$ & 92.76 & 90.89 & 90.84 & 90.84 & 90.92 \\
\hline$N$ & 3322 & 3322 & 3322 & 3322 & 3322 \\
\hline
\end{tabular}

All columns include control variables for gender of the child, whether the child receives free meal in school, whether the child has any disability, age of the child, whether the child enrolled in school late, age of the household head, a squared term age of household head, level of education of the household head, household size, a dummy for rural household, whether the household head is a female, educational expenditure, household poverty status, whether the school is a public school, month of interview and year of interview

Robust standard errors are in parenthesis $* * * p<0.01, * * p<0.05, * p<0.1$

$I V$ instrumental variables estimation

Table 7 Excluding children aged $14-15$ years

\begin{tabular}{|c|c|c|c|c|c|}
\hline & Write English/French & $\begin{array}{l}\text { Read English/ } \\
\text { French }\end{array}$ & Write native language & Read native language & $\begin{array}{l}\text { Do written } \\
\text { calculation }\end{array}$ \\
\hline & IV & IV & IV & IV & IV \\
\hline Distance to and from school & $-0.014 * * *(0.004)$ & $-0.013 * * *(0.004)$ & $-0.026^{* * * *}(0.005)$ & $-0.021^{* * * *}(0.004)$ & $-0.006^{*}(0.003)$ \\
\hline Child characteristics & Yes & Yes & Yes & Yes & Yes \\
\hline School characteristic & Yes & Yes & Yes & Yes & Yes \\
\hline Household characteristic & Yes & Yes & Yes & Yes & Yes \\
\hline Regional dummies & Yes & Yes & Yes & Yes & Yes \\
\hline Interview month & Yes & Yes & Yes & Yes & Yes \\
\hline Interview year & Yes & Yes & Yes & Yes & Yes \\
\hline \multicolumn{6}{|l|}{ Instrument } \\
\hline $\begin{array}{l}\text { Travel distance within } \\
\text { districts }\end{array}$ & $0.939^{* * * *}(0.119)$ & $0.938^{* * * *}(0.119)$ & $0.936^{* * *}(0.118)$ & $0.936^{* * *}(0.118)$ & $0.936^{* * * *}(0.118)$ \\
\hline $\begin{array}{l}\text { Cragg-Donald Wald F } \\
\text { statistic }\end{array}$ & 62.46 & 62.38 & 62.78 & 62.78 & 62.76 \\
\hline $\mathrm{N}$ & 2687 & 2687 & 2687 & 2687 & 2687 \\
\hline
\end{tabular}

All columns include control variables for gender of the child, whether the child receives free meal in school, whether the child has any disability, age of the child, whether the child enrolled in school late, age of the household head, a squared term age of household head, level of education of the household head, household size, a dummy for rural household, whether the household head is a female, educational expenditure, household poverty status, whether the school is a public school, month of interview and year of interview

Robust standard errors are in parenthesis $* * * p<0.01, * * p<0.05,{ }^{*} p<0.1$

$O L S$ ordinary least squares, $I V$ instrumental variables estimation 
substantially compromise our estimate. Rather, our core findings show a lower bound estimate of the impact of school travel time on learning outcomes.

\subsection{Omitted variable bias}

It is possible that our model might suffer from unobservable household and child level characteristics which could make our estimates biased and unreliable. We test for this possible bias by including additional set of control variables in the model. We include the region in which the child was born to capture the impact of migration on learning outcomes. Children who migrate to different locations are likely to have their education affected due to the new learning environment. We also include the child's ethnicity to isolate the impact of culture on children's education. Finally, we include religious affiliation in the model to tease out the possible impact of religious doctrine/commitments on children's education. The results in Table 6 show that including these variables does not compromise our estimates. For example, comparing the results in Table 8 with those in Table 2, one can notice that the coefficients and standard errors are stable except the coefficient for our instrument from the first stage regression that reduces. These suggest that omitted variable bias do not pose a major threat to our core findings.

\subsection{Using alternative instrument}

Finally, we check the reliability of our core estimates by using distance to the nearest periodic market as an alternative instrument. Periodic market is a major source of economic activities in many developing countries and are often located in areas with high population density as well as high volumes of economic activities (Smith1980; Bromley et al. 1975). Hence, we argue that districts with high density of periodic markets are better developed, which translates into the density of schools in those districts. The results in Table 9 are consistent with our core findings that longer travel distance to school impedes children's learning outcomes, with the largest effects observed for their ability to read and write in their native language. These estimates are substantially larger than our core estimates in Table 2.

\section{Conclusion and policy issues}

This study has examined the impact of school travel time on children's learning outcomes using household survey data from Ghana. Unlike previous studies, we utilised rich household data, which have fine-grained measures for learning outcome and school travel time, to examine the effect of travel time to school on learning outcomes. Our identification approach relied on district concentration of school to obtain exogenous variation in children's school travel time while controlling for time of interview fixed effects. The key findings are: First, longer travel time reduces children's ability to read and write in English or French, and their ability to read and write in any of their native languages. Second, relative to girls, boys' learning outcomes are largely compromised by the longer school travel time. Third, rural children's learning abilities are largely impacted by school travel time compared to 
Table 8 Including additional control variable

\begin{tabular}{|c|c|c|c|c|c|}
\hline & $\begin{array}{l}\text { Write English/ } \\
\text { French }\end{array}$ & $\begin{array}{l}\text { Read English/ } \\
\text { French }\end{array}$ & $\begin{array}{l}\text { Write native } \\
\text { language }\end{array}$ & $\begin{array}{l}\text { Read native } \\
\text { language }\end{array}$ & $\begin{array}{l}\text { Do written } \\
\text { calculation }\end{array}$ \\
\hline & IV & IV & IV & IV & IV \\
\hline Distance to and from school & $\begin{array}{l}-0.011^{* * * *} \\
(0.004)\end{array}$ & $-0.008^{* *}(0.003)$ & $-0.025^{* * *}(0.004)$ & $-0.021 * * *(0.004)$ & $-0.002(0.003)$ \\
\hline Child characteristics & Yes & Yes & Yes & Yes & Yes \\
\hline School characteristic & Yes & Yes & Yes & Yes & Yes \\
\hline Household characteristic & Yes & Yes & Yes & Yes & Yes \\
\hline Regional dummies & Yes & Yes & Yes & Yes & Yes \\
\hline Interview month & Yes & Yes & Yes & Yes & Yes \\
\hline Interview year & Yes & Yes & Yes & Yes & Yes \\
\hline \multicolumn{6}{|l|}{ Instrument } \\
\hline $\begin{array}{l}\text { Travel distance within } \\
\text { districts }\end{array}$ & $0.895 * * *(0.103)$ & $0.890 * * *(0.103)$ & $0.883 * * *(0.102)$ & $0.883 * * *(0.102)$ & $0.883^{* * * *}(0.102)$ \\
\hline $\begin{array}{l}\text { Cragg-Donald Wald F } \\
\text { statistic }\end{array}$ & 75.92 & 74.92 & 74.31 & 74.31 & 74.29 \\
\hline$N$ & 3704 & 3704 & 3704 & 3704 & 3704 \\
\hline
\end{tabular}

All columns include control variables for gender of the child, whether the child receives free meal in school, whether the child has any disability, age of the child, region of birth, ethnicity, religious affiliation, whether the child enrolled in school late, age of the household head, a squared term age of household head, level of education of the household head, household size, a dummy for rural household, whether the household head is a female, educational expenditure, household poverty status, whether the school is a public school, month of interview and year of interview

Robust standard errors are in parenthesis $* * * p<0.01, * * p<0.05,{ }^{*} p<0.1$

$O L S$ ordinary least squares, $I V$ instrumental variables estimation

Table 9 Using distance to nearest periodic market as instrument

\begin{tabular}{|c|c|c|c|c|c|}
\hline & $\begin{array}{l}\text { Write English/ } \\
\text { French } \\
\text { IV }\end{array}$ & $\begin{array}{l}\text { Read English/ } \\
\text { French } \\
\text { IV }\end{array}$ & $\begin{array}{l}\text { Write native } \\
\text { language } \\
\text { IV }\end{array}$ & $\begin{array}{l}\text { Read native } \\
\text { language } \\
\text { IV }\end{array}$ & $\begin{array}{l}\text { Do written } \\
\text { calculation } \\
\text { IV }\end{array}$ \\
\hline Distance to and from school & $-0.034 * *(0.012)$ & $-0.035 * *(0.014)$ & $-0.049 * * *(0.016)$ & $-0.058 * * *(0.019)$ & $-0.024^{* *}(0.011)$ \\
\hline Child characteristics & Yes & Yes & Yes & Yes & Yes \\
\hline School characteristic & Yes & Yes & Yes & Yes & Yes \\
\hline Household characteristic & Yes & Yes & Yes & Yes & Yes \\
\hline Regional dummies & Yes & Yes & Yes & Yes & Yes \\
\hline Interview month & Yes & Yes & Yes & Yes & Yes \\
\hline Interview year & Yes & Yes & Yes & Yes & Yes \\
\hline \multicolumn{6}{|l|}{ Instrument } \\
\hline $\begin{array}{l}\text { Distance to } \\
\text { periodic market }\end{array}$ & $0.300 * * *(0.089)$ & $0.286 * * *(0.088)$ & $0.296 * * *(0.088)$ & $0.295 * * *(0.089)$ & $0.237 * * *(0.011)$ \\
\hline $\begin{array}{l}\text { Cragg-Donald Wald F } \\
\text { statistic }\end{array}$ & 11.23 & 10.34 & 11.12 & 11.11 & 11.09 \\
\hline $\mathrm{N}$ & 3704 & 3704 & 3704 & 3704 & 3704 \\
\hline
\end{tabular}

All columns include control variables for gender of the child, whether the child receives free meal in school, whether the child has any disability, age of the child, whether the child enrolled in school late, age of the household head, a squared term age of household head, level of education of the household head, household size, a dummy for rural household, whether the household head is a female, educational expenditure, household poverty status, whether the school is a public school, month of interview and year of interview

Robust standard errors are in parenthesis $* * * p<0.01, * * p<0.05, * p<0.1$

$I V$ instrumental variables estimation 
those in urban areas. Fourth, children whose travel time to school is more than the $75^{\text {th }}$ percentile travel time (an equivalent of 30 minutes) have poorer learning outcomes compared to those who travel for less than 30 minutes to school. Finally, the channels through which travel time affects children's learning outcomes are through class hours missed and poor health.

Compared to previous works that have focused on school enrolment and attainment (Lavy 1996; Tansel 1997; Grootaert and Partinos 1999; Handa 2002), we have estimated the impact of travel time on intermediate outcomes. These intermediate outcomes better unmask vital information on the child's performance in school, which is critical for the smooth progression of the child in school as well as their human capital formation.

In conclusion, our study has shown that longer school travel time compromises children's learning outcomes, especially for those who walk to school. From a policy perspective, these findings show that policies that can mitigate long travel time to school can improve children's school performance. Considering that governments have limited resources with many competing needs, policies aimed at reducing school travel time should target children in rural locations who commute more than 30 minutes to school. Such policies can focus on supplying vehicles to basic school for school pick up and drop offs. This strategy can reduce the incidence of longer walking time to school, thereby reducing class hours missed, improve children's health and ultimately lead to better learning outcomes. Also, increasing community level school projects will have a long-lasting benefit of increasing children's ability to read and write.

Acknowledgements We are thankful to Shoshana Grossbard, Joyce Chen and two anonymous referees for their very constructive comments on the earlier version of this manuscript.

\section{Compliance with ethical standards}

Conflict of interest The authors declare that they have no conflict of interest.

Publisher's note Springer Nature remains neutral with regard to jurisdictional claims in published maps and institutional affiliations.

\section{Appendix 1: Modes of travel to school}

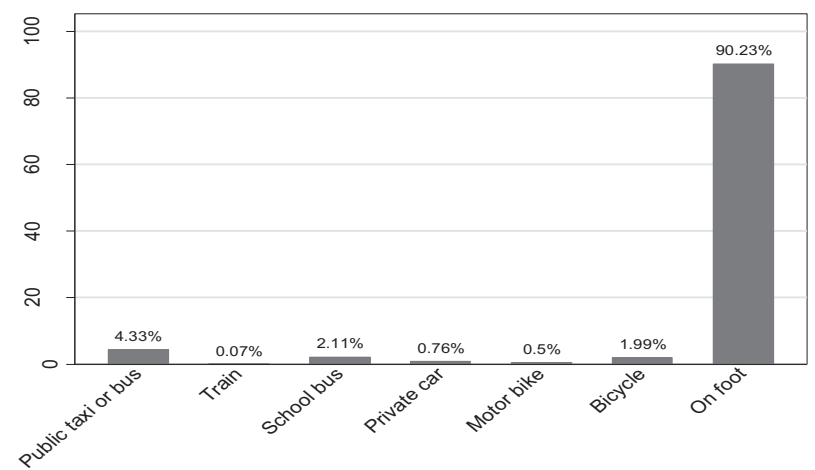




\section{Appendix 2: Distribution of learning outcomes across different genders and locations}

\begin{tabular}{lccllll}
\hline & Boys & Girls & Chi-square test & Rural & Urban & Chi-square test \\
\hline Write in English/French & 0.664 & 0.707 & $10.89^{* * *}$ & 0.599 & 0.868 & $371.22^{* * * *}$ \\
Read in English/French & 0.686 & 0.731 & $11.79 * * *$ & 0.626 & 0.881 & $340.25 * * *$ \\
Write in native language & 0.311 & 0.352 & $9.92^{* * *}$ & 0.253 & 0.490 & $286.70^{* * *}$ \\
Read in native language & 0.342 & 0.384 & $9.58^{* * *}$ & 0.279 & 0.532 & $310.79 * * *$ \\
Do written calculation & 0.762 & 0.783 & $3.36^{*}$ & 0.707 & 0.905 & $251.78^{* * *}$ \\
\hline
\end{tabular}

\section{Appendix 3: Modes of travel to school across percentiles of school travel time}

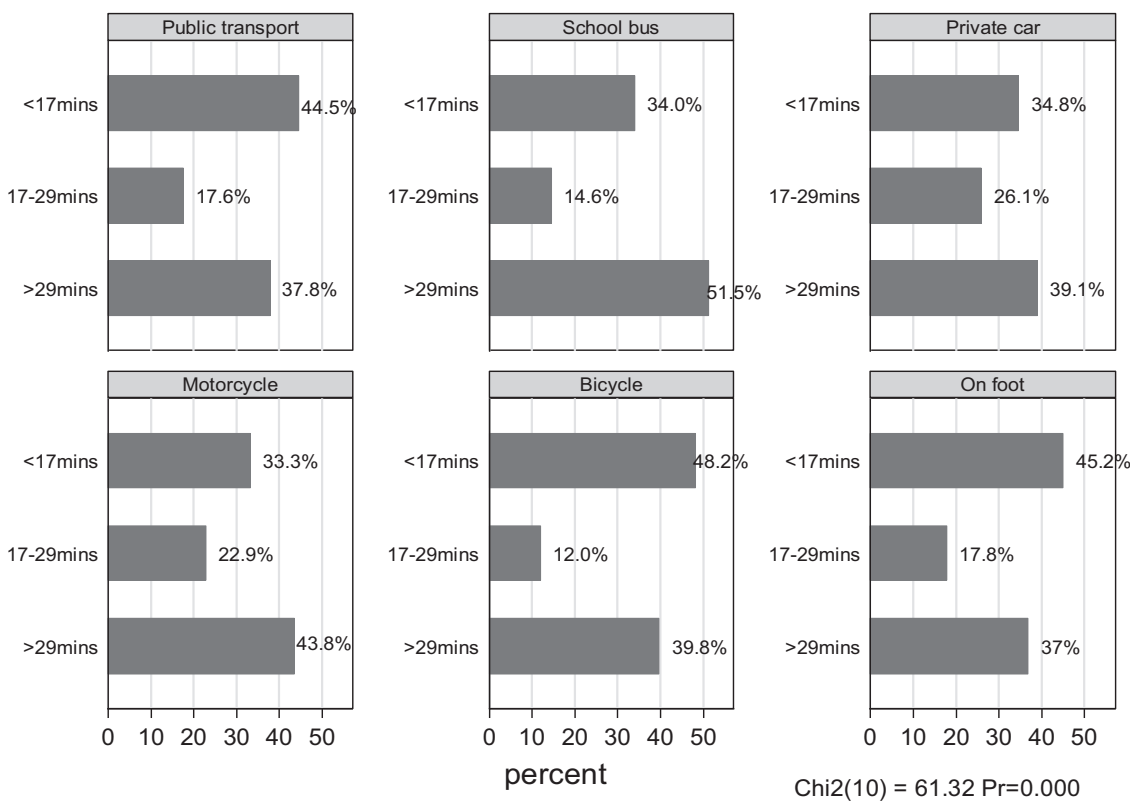

\section{References}

Abadzi, H. (2020). Accountability features and their implications for education policies. Comparative Education Review, 64(1), 66-86.

Abadzi, H. (2007). Absenteeism and beyond: instructional time loss and consequences. World Bank Policy Research Working Paper Series no. WPS4376. Washington, DC: World Bank.

Abdul-Mumuni, A., \& Koomson, I. (2019). Household remittance inflows and child education in Ghana: Exploring the gender and locational dimensions. Journal of Economic Research, 24(2), 197-222.

Afoakwah, C., Deng, X., \& Onur, I. (2020a). Women's bargaining power and children's schooling outcomes: evidence from Ghana. Feminist Economics, 20, 1-29. 
Afoakwah, C., Nghiem, S., Scuffham, P., Huynh, Q., Marwick, T., \& Byrnes, J. (2020b). Impacts of air pollution on health: evidence from longitudinal cohort data of patients with cardiovascular diseases. The European Journal of Health Economics, 21, 1-14.

Afridi, F. (2011). The impact of school meals on school participation: evidence from rural India. Journal of Development Studies, 47(11), 1636-1656.

Alderman, H., Orazem, P. F., \& Paterno, E. M. (2001). School quality, school cost, and the public/private school choices of low-income households in Pakistan. Journal of Human Resources, 304-326.

Becker, GS (1975). Human capital: a theoretical and empirical analysis, with special reference to education, 2nd edn, Chicago, USA: University of Chicago Press.

Brian, K. (2007). Human Capital: How what you know shapes your life. Paris: Organisation for Economic Cooperation and Development (OECD).

Bromley, R. J., Symanski, R., \& Good, C. M. (1975). The rationale of periodic markets. Annals of the Association of American Geographers, 65(4), 530-537.

Burke, K., \& Beegle, K. (2004). Why children aren't attending school: the case of Northwestern Tanzania. Journal of African Economies, 13(2), 333-355.

Cattaneo, M. A., Oggenfuss, C., \& Wolter, S. C. (2017). The more, the better? The impact of instructional time on student performance. Education Economics, 25(5), 433-445.

Caudill (1988). Practitioners corner: an advantage of the linear probability model over probit or logit. Oxford Bulletin of Economics and Statistics, 50(4), 425-427.

Dickerson, A., \& McIntosh, S. (2013). The impact of distance to nearest education institution on the postcompulsory education participation decision. Urban Studies, 50(4), 742-758.

Filmer, D. (2007). If you build it, will they come? School availability and school enrolment in 21 poor countries. The Journal of Development Studies, 43(5), 901-928.

Flannery, D., \& Cullinan, J. (2014). Where they go, what they do and why it matters: The importance of geographic accessibility and social class for decisions relating to higher education institution type, degree level and field of study. Applied Economics, 46(24), 2952-2965.

Fredrick, W. C., \& Walberg, H. J. (1980). Learning as a function of time. The Journal of Educational Research, 73(4), 183-194.

Frenette, M. (2006). Too far to go on? Distance to school and university participation. Education Economics, 14(1), 31-58.

Frenette, M. (2004). Access to college and university: Does distance to school matter?. Canadian Public Policy/Analyse de Politiques, 30, 427-443.

Gaddah, M., Munro, A., \& Quartey, P. (2016). Education subsidy and school enrolments in rural Ghana. International Journal of Educational Development, 46, 143-152.

Gelli, A., Aurino, E., Folson, G., Arhinful, D., Adamba, C., Osei-Akoto, I., \& Alderman, H. (2019). A school meals program implemented at scale in Ghana increases height-for-age during midchildhood in girls and in children from poor households: a cluster randomized trial. The Journal of Nutrition, 149(8), 1434-1442.

Grootaert, C., \& Partinos, H. (1999). The Policy Analysis of Child Labor. A Comparative Analysis. New York, NY: St Martin's Press.

Ghana Statistical Service (GSS). (2019). "Ghana Living Standards Survey Round 7 (GLSS 7)". Main Report, Accra available at https://open.africa/dataset/ghana-living-standards-survey-glss-7-2017.

Handa, S. (2002). Raising primary school enrolment in developing countries. The relative importance of supply and demand. Journal of Development Economics, 69, 103-128.

Heckman, J. J. (2000). Invest in the very young. Chicago: Ounce of Prevention Fund and the University of Chicago Harris School of Public Policy Studies.

Lavy, V. (1996). School supply constraints and children's educational outcomes in rural Ghana. Journal of Development Economics, 51(2), 291-314.

Leibowitz, A. A. (2003). In-home training and the production of children's human capital. Review of Economics of the Household, 1(4), 305-317.

Mincer, J. (1958). Investment in human capital and personal income distribution. Journal of Political Economy, 66(4), 281-302.

Quiggin, J. (1999). Human capital theory and education policy in Australia. Australian Economic Review, 32(2), 130-144.

Schultz, T. W. (1961). Investment in human capital. The American Economic Review, 51, 1-17.

Smith, R. H. (1980). Periodic market-places and periodic marketing: review and prospect-II. Progress in Human Geography, 4(1), 1-31.

Spiess, C. K., \& Wrohlich, K. (2010). Does distance determine who attends a university in Germany? Economics of Education Review, 29(3), 470-479. 
Tansel, A. (1997). Schooling attainment, parental education, and gender in Cote d'Ivoire and Ghana. Economic Development and Cultural Change, 45(4), 825-856.

United Nations Educational, Scientific and Cultural Organization. (2017). More than one-half of children and adolescents are not learning worldwide. http://uis.unesco.org/sites/default/files/documents/fs46more-than-half-children-not-learning-en-2017.pdf.

World Bank. (2019) World Development Indicators. https://data.worldbank.org/indicator/SE.PRM.ENRR? locations $=1 \mathrm{~W}$.

World Bank. (2003). Lifelong Learning in the Global Knowledge Economy: challenges for developing countries. Washington: World Bank. http://documents1.worldbank.org/curated/en/5281314687499 57131/pdf/Lifelong-learning-in-the-global-knowledge-economychal-lenges-for-developingcountries.pdf. 